\title{
OS PROGRAMAS SOCIAIS BRASILEIROS E SUAS INFLUÊNCIAS
}

Caroline Ferreira Da Silva, Hugo Bárrios Marino, Edilene Mayumi Murashita Takenaka

Universidade do Oeste Paulista, Curso de Administração, Presidente Prudente, SP. E_mail: caroline ferreira31@outlook.com

\section{RESUMO}

Os programas sociais brasileiros tornaram-se uma das principais alternativas para milhões de famílias de baixa renda como forma de sobrevivência. Atualmente, esses programas atendem aproximadamente 50 milhões de pessoas. Para o Governo, o aumento do impacto positivo na redução da extrema pobreza melhora a economia do país devido ao maior consumo da população. O objetivo geral da pesquisa foi analisar os impactos aferidos pelos programas sociais existentes. Para tanto, o procedimento metodológico utilizado foi a metodologia qualitativa, que tem caráter exploratório, através de pesquisa bibliográfica e pesquisas documentais. Com o aprofundamento das pesquisas, conclui-se que programas analisados possuem características muito positivas para seu público-alvo, alcançando os objetivos propostos e melhorando a vida de milhões de brasileiros.

Palavras-chave: Programas Sociais. Organizações. Renda Complementar

\section{THE BRAZILIAN SOCIAL PROGRAMS AND THEIR INFLUENCES}

\begin{abstract}
Brazilian social programs have become one of the main alternatives for millions of low-income families as a means of survival. Currently, these programs serve approximately 50 million people. For the Government, the positive impact on reducing extreme poverty improves the economy of the country, due to the greater consumption of the population. The general objective of the research was to analyze the impacts of existing social programs. For that, the methodological procedure used was the qualitative methodology, which has an exploratory character, through bibliographical research and documentary research. With the deepening of the researches, it is concluded that analyzed programs have very positive characteristics for their target audience, reaching the proposed objectives and improving the lives of millions of Brazilians.
\end{abstract}

Keywords: Social Programs, Organizations, Complementary Income 


\section{INTRODUÇÃO}

Os programas sociais são iniciativas criadas pelo Governo para melhorar as condições de vida da população de baixa renda e de extrema pobreza do país. 0 intuito principal, durante o processo de implantação dos programas, era reduzir o nível de famílias consideradas extremamente pobres, dando um auxílio financeiro enquanto essas famílias necessitassem, visando garantir sua sobrevivência e, com isso, poder melhorar suas condições de vida.

No final dos anos 90, o governo do então presidente Fernando Henrique Cardoso colocou em prática alguns programas sociais. Um dos mais conhecidos era o Bolsa Escola, que tinha como principal objetivo combater a pobreza, a exclusão social e erradicar o trabalho infantil.

Por volta de 2003, no governo do presidente Luiz Inácio Lula da Silva, surge então o programa Bolsa Família, composto pela fusão dos programas que eram utilizados no governo anterior.

A partir de 2003 o Cadastro Único ${ }^{1}$ se tornou o principal instrumento da nação para a seleção e a inclusão de famílias de baixa renda em programas federais.

Para realizar o cadastro em um programa social, o responsável pela renda familiar deve procurar um CRAS - Centro de Referência em Assistência Social com uma série de documentos e ser compatível com as requisições de renda suficientes para fazer jus ao benefício.

Para o governo, isso faz com que a economia do país melhore, pois, a partir do momento que a classe de extrema pobreza começa a ter uma redução, pode-se levar em consideração que a nação está se desenvolvendo. A qualidade de vida dos beneficiados com os programas melhora, e isso faz o Brasil sair do mapa da extrema pobreza.

O presente trabalho teve por objetivo geral da pesquisa, analisar os impactos aferidos pelos programas sociais existentes. Para tanto, dois programas foram escolhidos para análise, os programas Bolsa Família, Luz para Todos e a Tarifa Social de Energia Elétrica, cujo intuito primário é auxiliar famílias necessitadas.

\section{ASPECTOS METODOLÓGICOS}

Segundo Severino (2007), a metodologia é a explicação minuciosa, detalhada, rigorosa e exata de toda ação desenvolvida no método do trabalho de pesquisa.

Dessa forma, foi utilizado o método de uma pesquisa qualitativa a partir de revisão bibliográfica com levantamento de dados junto à documentação indireta em fontes primárias e secundárias. (MASCARENHAS, 2012)

Utilizou-se ainda a prática de pesquisa exploratória por meio da qual se realizou o estudo, a análise, o registro e a interpretação dos fatos sem a interferência do pesquisador, e para isso foi utilizada a revisão teórica tendo como instrumento de pesquisa empregado para a coleta de dados a observação sistemática. (LAKATOS e MARCONI, 1992)

\section{RESULTADOS}

Segundo Giamgiagi, Villela, Castro e Hermann (2011), a política econômica no Brasil de 1945 a 1955 refletiu não apenas as ideias e os interesses econômicos e políticos em disputa doméstica, como também as restrições de ordem interna e externa. Temos, assim, uma época marcada por uma série de conflitos internos, enquanto o foco deveria estar no crescimento e desenvolvimento da nação como um todo.

De acordo com Castro e Modesto (2011), a primeira metade dos anos de 1990 marca a posse do primeiro presidente eleito pelo voto direto, fato que não ocorria no país desde 1961. Com isso, a população mostra alguma reação ao regime fechado em que o país se encontrara até

\footnotetext{
${ }^{1}$ Cadastro Único: O Cadastro Único é um conjunto de informações sobre as famílias brasileiras em situação de pobreza e extrema pobreza. Essas informações são utilizadas pelo Governo Federal, pelos Estados e pelos municípios para implementação de políticas públicas capazes de promover a melhoria da vida dessas famílias. Disponível em:<http://www.caixa.gov.br/cadastros/cadastro-unico/Paginas/default.aspx>. Acesso em: 15 mar. 2018
} 
alguns anos atrás e a democracia passa a ter forças novamente pelo comando de Fernando Collor de Mello. A partir dessa data, uma série de mudanças passam a ocorrer política e economicamente.

Por meio dos ideais apresentados por Collor, começam a ser consideradas as camadas excluídas da sociedade, como trabalhadores rurais e braçais, funcionárias domésticas, lixeiros, entre tantas outras profissões antes subjugadas. Nessa época, a população sentiu que o governo realmente iria propor mudanças e começou a sentir sua verdadeira força, pois sempre foi a grande maioria. (CASTRO e MODESTO, 2011)

Com o fim da era Collor, ocorre uma grande rotatividade nos cargos governamentais, que encontram estabilidade quando assume o presidente Fernando Henrique Cardoso, que reintegrou a economia com um dos maiores legados de seu governo, o Plano Real, cujas fases de implantação permitem à economia voltar a estabilizar e inicia um ciclo de crescimento.

Assim, o novos governos que se seguiram viram-se impulsionados a cumprir as promessas feitas por Collor alguns anos atrás, com o principal intuito de aumentar $0 \mathrm{IDH}^{2}$ e formar mais profissionais capazes e pensantes, trazendo mais cultura e desenvolvimento ao país.

Assim, as políticas macroeconômicas passam a ser utilizadas com maior requinte ao considerar a importância de distribuir recursos e promover ações centralizadas em aspectos sociais.

As políticas sociais se diferenciam entre aquelas que pagam benefícios em dinheiro e aquelas que prestam serviços sociais aos cidadãos. (CARNEIRO e MATIJASCIC, 2011)

Em 2004, o Programa Bolsa Família é decretado por lei como programa de transferência de renda a partir da unificação de outros programas não contributivos anteriormente existentes: Bolsa Escola, Cartão Alimentação, Auxílio-Gás e Bolsa Alimentação. (ABRAHÃO e MODESTO, 2010)

O Bolsa Família ${ }^{3}$ é um programa de transferência direta de renda direcionado às famílias em situação de pobreza e de extrema pobreza em todo o país, de modo que consigam superar a situação de vulnerabilidade e pobreza. Tal programa surge para dar apoio para famílias que não possuem uma renda fixa mensal.

O valor disponível pode sofrer variações perante a quantidade de beneficiários existentes na família e entre seus objetivos estão: a inclusão social das famílias premidas pela miséria, com alívio imediato de sua situação e o estímulo a avanços em sua educação e saúde para interromper o ciclo Inter geracional de reprodução da pobreza.

Em 2017 foram registrados cerca de 13,8 milhões de brasileiros que se beneficiam do Programa Bolsa Família. Esse dado foi disponibilizado pelo governo, para o qual Programa realizou a distribuição de um total de $\mathrm{R} \$ 2,48$ bilhões para brasileiros que mais precisam do benefício.

Em novembro de 2003 foi lançado, por meio de decreto ${ }^{4}$, o Programa Luz para Todos, com o desafio de acabar com a exclusão elétrica no país, com meta de levar o acesso à energia elétrica, gratuitamente, para mais de 10 milhões de pessoas do meio rural até o ano de 2008. O Programa é coordenado pelo Ministério de Minas e Energia, operacionalizado pela Eletrobrás e executado pelas concessionárias de energia elétrica e cooperativas de eletrificação rural em parceria com os governos estaduais.

O mapa da exclusão elétrica no país revela que as famílias sem acesso à energia estão majoritariamente nas localidades de menor índice de desenvolvimento humano e de famílias de baixa renda: cerca de $90 \%$ delas têm renda inferior a três salários mínimos.

\footnotetext{
${ }^{2}$ Índice de desenvolvimento humano: é uma medida resumida do progresso a longo prazo em três dimensões básicas do desenvolvimento humano: renda, educação e saúde. Disponível em:

<http://www.br.undp.org/content/brazil/pt/home/idh0.html>. Acesso em:17/04/2018

${ }^{3}$ Disponível em: <http://www.caixa.gov.br/programas-sociais/bolsa-familia/Paginas/defau. aspx> Acesso em:15/04/2018

${ }^{4}$ Disponível em:

<http://www.planalto.gov.br/ccivil_03/decreto/2003/D4873.htm>. Acesso em 24 abr. 2018
} 
Para colocar um fim nessa realidade, o governo define como objetivo que a energia seja um vetor de desenvolvimento social e econômico dessas comunidades, contribuindo para a redução da pobreza e aumento da renda familiar.

A tarifa social de eletricidade, decretada em lei de 20 de janeiro de $2010^{5}$, é um benefício regulamentado pela $\mathrm{ANEEL}^{6}$, que libera descontos na conta de luz de consumidores caracterizados como baixa renda. Esse desconto pode chegar a $65 \%$ e ainda dá a possibilidade de parcelamento de conta atrasadas.

O Programa tem priorizado os beneficiários do Programa Brasil sem Miséria, escolas rurais, quilombolas, indígenas, assentamentos, ribeirinhos, pequenos agricultores, famílias em reservas extrativistas afetadas por empreendimentos do setor elétrico e poços de água comunitários. ${ }^{7}$

\section{DISCUSSÕES}

O programa Luz Para Todos proporcionou para a população menos favorecida melhorias no seu bem-estar e, ao mesmo tempo, gerou novos empregos. Isso acontece devido à implantação da energia elétrica em áreas mais pobres, fazendo com que algumas empresas comecem a migrar para essas áreas e, com isso, gerando novas vagas no mercado de trabalho.

Já o programa Bolsa Família auxiliou milhares de famílias existentes na faixa da extrema pobreza, proporcionando o bem-estar e melhorando a qualidade de vida com a renda disponibilizada pelo governo.

\section{CONSIDERAÇÕES FINAIS}

Com embasamento nesta pesquisa podemos perceber que os programas analisados possuem características muito positivas para seu público-alvo, alcançando os objetivos propostos e melhorando a vida de milhões de brasileiros.

Entretanto, o maior problema que envolve os programas são as incertezas quanto ao futuro, pois os programas sociais podem, em determinadas circunstâncias serem considerados um alternativa eterna de sustentação. Seus beneficiários, em alguns casos, entram em um ciclo vicioso, no qual se acredita que quando se parar de utilizar os programas, mesmo tendo uma renda fixa, terá a possibilidade de levá-los novamente a pobreza.

\section{REFERÊNCIAS}

ABRAHÃO, J de C. e MODESTO L. (Orgs). Bolsa família 2003-2010: avanços e desafios. 2 vol. Brasília: IPEA, 2010.

CARNEIRO, R. M. \& MATIJASCIC, M. (Orgs.) Desafios do desenvolvimento brasileiro. Brasilia, 2011. Disponivel em

http://www.ipea.gov.br/portal/index.php?option=com content\&view=article\&id=12321:desafiosdo-desenvolvimento-brasileiro\&catid=266:2011\&directory=1>. Acesso em 12/02/2018.

CASTRO, J.A; MODESTO, L. Bolsa família 2003-2010: avanços e desafios. Brasília: IPEA, 2010. 2 ed.(344p).

GIAMBIAGI, F; VILLELA, A; CASTRO, L. B. e HERMANN, J (Orgs). Economia brasileira contemporânea 1945- 2010. 2 ed. Rio de Janeiro: Elsevier, 2011.

\footnotetext{
${ }^{5}$ Disponível em:

<https://www.planalto.gov.br/ccivil_03/_Ato2007-2010/2010/Lei/L12212.HTM>. Acesso em: 08/02/2018

${ }^{6}$ Agencia Nacional de Energia Elétrica

${ }^{7}$ Disponível em: <http://www.pac.gov.br/agua-e-luz-para-todos/luz-para-todos> Acesso em:12/02/2018 
LAKATOS, M. E. MARCONI, M. A. Metodologia do trabalho cientifico. 4 ed. São Paulo. Revista e Ampliada. Atlas, 1992.

MASCARENHAS, S. Metodologia científica. São Paulo:Pearson, 2012.

SEVERINO, A.J. Metodologia do trabalho científico. 23. ed. São Paulo: Cortez, 2007. 